\title{
The Age of Artificial Intelligence and Robotics: Challenges and Issues
}

\author{
Slavica Kodish \\ Southeast Missouri State University
}

\begin{abstract}
Artificial intelligence continues to advance and play an increasingly prominent role in different aspects of human life. We are also witnessing the emergence of an increasing number of various types of bots equipped with sophisticated software that enables them to interact and communicate with humans. Developments in artificial intelligence and robotics also raise challenges and issues with implications for ethics and leadership. In this article, major challenges and issues brought about by the developments in artificial intelligence and robotics are addressed. As creators of artificial intelligence and various types of bots, we have an ethical responsibility toward our creation and toward other humans. As leaders, we are to be aware of challenges and issues in order to deal with them in a prudent and timely manner.
\end{abstract}

Keywords: artificial intelligence; bots; interaction; robotic agency

\section{INTRODUCTION}

Artificial intelligence (AI) is advancing at a rapid pace. Bold new developments have taken place and impressive strides have been made since 1997 when the computer named Deep Blue defeated Gary Kasparov, the world's chess champion, and since 2011 when IBM's computer named Watson trounced two well-prepared and knowledgeable human Jeopardy contestants and won the first prize. Developments in robotics are also impressive.

Bots equipped with sophisticated software work in warehouses and assembly lines and perform many tasks that humans used to perform. Bots participate in military efforts and work in areas of power plants and nuclear power plants that are dangerous for humans. Some humanoid bots, such as the bot Sophia, have gained a celebrity status.

The era of artificial intelligence and robotics is upon us. Developments are fascinating in many ways. They are also creating new challenges and issues in various aspects of human lives, including work and social and relational matters. Furthermore, they are beginning to affect the cultural milieu as advancements in AI continue and as more advanced bots begin to impact our reality.

In this article, attention is drawn to recent advancements in AI and robotics and to challenges and issues brought about by the advancements and developments. Special attention is given to relational matters in view of ethical dilemmas that interaction and communication with AI and bots creates. Organizational sequence of the article follows its purpose and focus. In the first section, as a foundation for future discussion, the most recent developments in AI and robotics are described. In the following section, economic and social changes are addressed, followed by issues pertaining to personhood and agency. Interaction and communication with AI and bots, including theoretical issues and two specific ethical matters, are then addressed. The final section contains concluding thoughts. 
Methodologically, this article has an eclectic foundation. Developments in AI and robotics go beyond the fields of computing and mathematics and are complex and interdisciplinary in nature. Due to the complexity of the issue, a variety of interdisciplinary sources served as a basis for the content of the article: business, ethics, mass media, AI industry; economics, technology, leadership, relational theory, and communication.

\section{Terminology}

Terminology in the area of AI and robotics can be confusing. For the purpose of ensuring clarity, the term artificial intelligence or $A I$, for short, is used to denote sophisticated software, whether in the form of a computer algorithm or software installed in a machine capable of performing specific tasks. The term robot or bot, for short, refers to machines equipped with artificial intelligence that perform a variety of tasks. Some bots have a human form and are typically referred to as humanoid bots, or, to be more specific, as geminoids if they look like women, or androids, if they resemble men. Another term that may create confusion refers to individuals or teams who create robots. Are they creators, or designers, or programmers? Creators of humanoid bots tend to refer to themselves as designers, so in this text, the term designer is used to denote those who design, create, and program bots.

\section{THE DAWN OF SUPER INTELLIGENCE}

Developments in the area of AI and robotics are many. This section contains an overview of the most recent developments as a basis for the discussion of resulting challenges and issues.

Robots are now performing various tasks that humans used to perform. Robots, for example, assist in various stages of manufacturing due to their physical strength and durability. Some robots are designed to help in the fast-food industry. Flippy, the burger-making bot, can make hamburgers much faster than any human being. It also uses much less space than a team of workers and does not mind the heat (Albrecht, 2018; Dean, 2020). Special bots are participating in the fight against the COVID-19 pandemic. They disinfect hospitals by moving around and emitting short wavelength UV-C light that destroys pathogens (Allison, 2020). Honda's ASIMO (Advanced Step in Innovative Mobility) talks, answers questions, dances, walks straight and sideways, shakes hands, and is very polite. Other types of robots do house chores and provide various other duties. Mark Zuckerberg, for example, has a personal robot named Jarvis who "can turn the house lights on and off, play songs, recognize who's at the front door and let people in, manage the temperature, activate a toaster - and has even been programmed with a sense of humor" (Burke, 2016, para. 2). Among recent developments is Hal -- a childlike patient simulator bot used for training medical students. Hal can talk, express emotions, move, and respond both verbally and nonverbally to various stimuli. Hal is so lifelike that, according to some reports, it "creeped out" the trainees (Papadakis, 2018). Robots are also expected to play a larger role in decision making. By 2025, robots may be sitting on the Board of Directors (see Singh, 2017).

Special robots are being designed to help humans with their emotional and relational needs. For example, Pepper Robots are assisting the elderly in Japan. Another example is the Harmony AI designed to meet emotional needs of their owners (see Nash, 2017). PARO (Personal Assistive Robot), the therapeutic bot that looks like a baby seal, assists the elderly in nursing homes by delivering emotional support that is typically provided by pets. The chatbot Replika provides companionship and solace to humans who need someone to talk to (see Murphy, 2019). Artificial intelligence is also used in medicine, agriculture, and data mining.

Sophisticated computers predict with much more accuracy than physicians when the heart will fail (Gallagher, 2017a) and recognize skin cancer equally well as physicians (Gallagher, 2017b). AI is being used in agriculture to identify problems such as fungus growth and water shortages in corn and soybean crops several weeks before experts could even notice a problem (McFarland, 2017). The use of AI for collecting enormous amounts of data about individuals throughout the world is becoming common (see Harrari, 2020). 
Roborace motorsport competitions that feature self-driving cars are now an annual event (Belton, 2019). AlphaZero, the chess playing bot, is showing not only skill, but intuition and creativity, and is playing chess in a humanlike manner. According to the leader of the program, this may suggest a turning point in artificial intelligence:

we're starting to understand that many abilities, like intuition and creativity, that we previously thought were in the domain only of the human mind, are actually accessible to machine intelligence as well. And I think that's a really exciting moment in history (as quoted in Bunker, 2018, para. 6)

The above examples of recent developments in the realm of AI and robotics indicate that $\mathrm{AI}$ and bots are increasingly becoming a part of our reality and a part of a new world that is emerging and intensifying. The capabilities of AI and bots are fascinating. What is even more fascinating is the speed of advancement and sophistication of AI and bots and the likelihood of an exponential advancement and sophistication in the future. According to Frank (2018), "intelligent systems, like those powered by the latest round of machine learning software, aren't just getting smarter: they're getting smarter faster" (para $3)$. The developments in AI and robotics are affecting various aspects of human life.

\section{ECONOMIC AND SOCIAL CHANGE}

A fundamental shift in the area of work is under way (see Bucklin, 2019; Ford, 2015; Schwab, 2016a, 2016b). Machines are no longer tools that will help increase the productivity of workers; rather "the machines themselves are turning into workers" (Ford, 2015, p. xii). According to Schwab (2016b), new technologies will be "fusing the physical, digital and biological worlds, impacting all disciplines, economies and industries, and even challenging ideas about what it means to be human" (para. 3). Brynjolfsson and McAfee (2014) write that we are at a turning point: "Computers and robots will keep evolving and will learn to do new things at an amazing pace. That's why we're at an inflection point today, at the dawn of what we call the Second Machine Age" (as cited. in Bernstein \& Raman, 2015). Changes that are taking place are sometimes referred to as the fourth industrial revolution (see Marr, 2016; Schwab, 2016a). Marr (2016) writes that steam and water power came first; electricity and assembly lines followed; computerization came next. The fourth industrial revolution, unlike the previous three, is qualitatively different due to AI and robotics. We can expect "smart factories in which machines are augmented with web connectivity and linked with a system that can visualize the entire production chain and make decisions on its own" (see Marr, 2016, para 1).

The impact of the fourth industrial revolution is expected to create unprecedented economic and social changes. Ford $(2015,2016)$ believes that machines will increase productivity, on one hand, and bring unemployment, on the other. Brynjolfsson \& McAfee also anticipate increased unemployment due to the role that intelligent machines are expected to play in the near future.

AI is expected to replace humans in a variety of professions. Menial jobs seem to be facing the greatest risk, but as the machines evolve, many jobs may become replaceable and, possibly, hundreds of millions of people throughout the world may be left without jobs (see Wolf, 2019). McChesney (2016) predicts widespread unemployment and au uncomfortable new "economic reality." Younger investors already prefer robo-advisers to human brokers when planning their financial future. Robo-advisers have proven to be able to provide superior advice on stocks and risks compared to their human counterparts and are currently "threatening the jobs of thousands of human brokers in the \$20 trillion US wealth management business." (Byrne, 2017, para 3). Developments in AI and robotics are also generating other challenges and issues. 


\section{PERSONHOOD AND AGENCY}

An issue that contains both ethical and legal connotations refers to personhood. If intelligent software and intelligent bots show sentience, perform tasks that humans typically perform, or even outdo humans, do they have personhood? The tangible world on our planet comprises a number of major categories that include humans, flora, fauna, and inanimate objects, including human-made objects such as machines. AI and bots are made by humans, but are they machines? This question is especially pertinent in the case of humanoid bots. Are they machines? Are they humans? Can they be both machines and humans? If they can talk, if they can answer questions, if they can express feelings and help people express feelings, if they can help humans develop an emotional response, and if they behave like humans, what or who are they?

Back in 1950, the mathematician and computer scientist Alan Turing developed what is known as the Turing test for evaluating a machine's ability to exhibit intelligent behavior that equals human abilities and is indistinguishable from human abilities. During the Turing test session, the evaluator is to converse with a machine using a natural language. If the machine answers questions in the same manner in which a human being would answer them, the machine is considered to have passed the test. Some present-day intelligent machines possess abilities that may enable them to pass the Turing test. Does this suggest that if intelligent machines exhibit communication abilities on par with those of humans, we can consider them human, or that we need to develop new ways to delineate between machines and humans?

This issue will become even more complicated as the work on AI continues in the direction somewhat surreptitiously called general intelligence. The term refers to machines that will have the ability to outdo humans in almost everything that makes humans "human" - use of natural languages, decision making, self-awareness, learning, planning, motion, creativity, and social intelligence. In short, general intelligence refers to machines that will, in a Shakespearian sense, "outhuman" humans. In the future, the outhumaning of humans may take a step further.

A possibility exists that advancements in general intelligence may lead to singularity - the point at which AI becomes smarter than us, humans, and starts improving itself at an exponential rate. Singularity is still a speculation, but it needs to be taken into consideration when discussing AI and its future interaction with humans. The issue of agency seems to complicate the question of potential personhood.

\section{Robotic Agency}

The notion of texts as actors or agents in the process of organizing and the discursive nature of organizing have been widely accepted (see, e.g., Cooren, 2004; Fairhurst \& Putnam, 2004; Heracleous \& Barrett, 2001; Heracleous \& Marshak 2004; Pålshaugen, 1998; Putnam \& Fairhurst, 2001; Taylor \& Robichaud, 2004; Tompkins and Wanca-Thibault, 2001). According to Cooren (2004), "text in all its forms (written, oral, iconic) can display a form of agency, that is, it can make a difference" (p. 2). If texts have agency and are impacting human behavior, are we to expect that intelligent machines also have agency? If so, will their agency be considered nonhuman or human?

Cooren (2004) addresses the role of nonhuman agency and its relationship with human agency. Although he had in mind texts and objects rather than artificial intelligence and bots when he wrote the article, his words from 16 years ago require attention:

Recognizing nonhuman agency does not reduce human agency to an empirical artefact. On the contrary, it shows how a hybrid association between humans and nonhumans enables people to do things that they could not do otherwise. A focus on nonhuman agency paves the way to recognizing hybrid agency, that is, the way humans can appropriate what nonhumans do. They exchange properties with each other; the gun is different in a person's hand, just as the person is different with the gun in his hand. (p. 3)

Existence of nonhuman agency and tis impact on humans suggests that we, humans, may be changed through encounters and interaction with AI and bots. If using an object impacts us so much that our 
properties are changed, it is to be expected that we may be changed significantly more when we interact with an intelligent humanoid bot, or a future super-intelligent bot whose capabilities are similar to ours or even exceed ours.

\section{INTERACTION AND COMMUNICATION}

A cluster of issues and challenges that requires attention centers on both practical and theoretical aspects of interaction and communication. How are we to interact and communicate with intelligent software and intelligent bots and how are we to treat them? Can communication models and theories that are used to explain human interaction and communication and that serve as a basis for understanding human interaction and communication be applied to instances of human-to-AI and bot interaction and communication? Some ethically questionable uses of AI and bots pose an additional challenge. Yet another issue, seemingly simpler than the previous ones, regards linguistic matters. In the following paragraphs, the cluster of issues and challenges pertaining to interaction and communication are addressed in more detail.

\section{A New Communication Style}

$\mathrm{AI}$ and bots are a new interactant and a new collocutor in the process of interaction and communication, and we seem to lack both practical guidelines and a theoretical foundation for such an endeavor. What is becoming obvious, though, is that AI and bots communicate in a manner that stands out from typical human communication style at the beginning of the $21^{\text {st }}$ century.

$\mathrm{AI}$ and bots are being designed to communicate politely, respectfully, and thoughtfully, and to express understanding and compassion. The rhetorician Burke, when pointing out that human communication is not absolute or perfect, wrote that "only angels communicate absolutely" (Burke, 1965, p. 139). Burke's statement does not seem to apply to AI and bots. Intelligent machines can, indeed, avoid human imperfections and flaws when communicating, and communicate in Burke's words "absolutely," that is, perfectly and flawlessly. AI's perfect communication style stands out when contrasted with our human ways of communicating, and especially at a time of increased incivility, objectification, and disregard for other human beings.

Over the past several decades, an increasing number of scholars and philosophers has brought attention to a disconcerting development - that we live in an age characterized by objectification, incivility, or disrespect (see, e.g., Arnett \& Arneson 1999; Buber 1958, 1965; Eisler 1988; Fromm 1956; Levinas, 1979; Montagu \& Matson 1983; Postman 1999; Tannen, 1998). Intelligent machines are programmed to be civil and respectful and to express empathy and understanding. The issue of interacting with $\mathrm{AI}$ and bots and especially with geminoid and android bots is, indeed, complex. Two ethically questionable uses of bots complicate the issue.

\section{Ethically Questionable Uses of Bots}

The world of artificial intelligence and robotics is in many ways beginning to parallel the human world. Just as in the human world human behavior can be more or less ethical or even unethical, we can see similar developments in the AI and robotics universe. In the following paragraphs, two specific problematic uses of AI and bots are addressed.

\section{Terminator Bots}

Existence of the so called terminator bots - intelligent machines capable of destroying humans - may sound like science fiction. Terminator bots not only exist, but the resources invested in making them more lethal and advanced are almost endless (see Barnes \& Chin, 2018). In the Terminator movies that propelled Arnold Schwarzenneger into fame, terminator robots are autonomous and indistinguishable from humans. Current real-life terminator bots have not reached that stage yet: they are distinguishable from humans and they require a human controller. Research is under way, however, to develop terminator bots that will be autonomous (see Tegmark, 2017). The existence of terminator robots raises serious 
ethical questions: Is it ethical to create terminator-robots? What are the risks that accompany the creation of future autonomous terminator robots? Another questionable use of robots refers to use of robots for sexual pleasure.

\section{Sexbots}

Some humanoid robots are being used for sex and prostitution. They are referred to as sexbots and are available at a relatively reasonable rate in the brothels "employing" them. For the time being, sexbots have the shape of attractive grown-up women and men, but since they are intended to meet all customers' needs, some other forms and shapes are to be expected, which raises additional ethical questions and concerns. Yet another area of challenges and issues pertaining to interaction and communication refers to the lack of a theoretical foundation for explaining human-to-AI and bot interaction and communication.

\section{Theoretical Issues}

The number of texts on interaction and communication with $\mathrm{AI}$ and bots is growing. Authors tend to favor the relational approach - rather than viewing AI and bots as machines, authors tend to view them as a new partner in the process of interaction and communication. For example, Coeckelbergh (2014) proposes a relational approach that may be understood to include equality between AI and bots, on one hand, and humans, on the other. Gunkel $(2012,2014)$ points out to the need to reconsider the rules of interaction. Torrance (2014) believes that an objective standard should be used when deciding whether AI and bots are equal to us, humans, such as the standard of conscious satisfaction or suffering: if a bot is capable of expressing conscious satisfaction or suffering, as biological beings are, its moral status would be equal to that of humans. Bostrom (2014) and Tegmark (2017), respectively, address the relevance of interaction and communication with $\mathrm{AI}$ and bots without providing definitive answers.

Extant theories and models of interaction and communication have been created with humans in mind, and, therefore, lack the explicatory potential for human-to-AI and bot interactions and communication. In the following paragraphs, a review of major models and theories that serve as a basis for understanding and explaining human interaction and communication is provided in an attempt to illustrate theoretical issues of human to $\mathrm{AI}$ and interaction and communication.

\section{The Shannon-Weaver Model}

The Shannon-Weaver model of communication serves a useful purpose for describing the components of the communication process. Incidentally, this model was created about seven decades ago with the purpose of explaining human to machine communication.

The model is simple and precise: the sender's responsibility is to create a message and send it to the receiver. A channel with, preferably, not much interference, allows the message to travel from the sender to the recipient. Communication in this model is perceived as a relatively facile flow of information from the sender to the receiver. Major responsibility lies with the sender who is to put together the message and send it to the receiving party

The model presupposes a passive recipient (Axley, 1984; Kodish \& Pettegrew, 2008; Reddy, 1979). Various forms of AI and bots are being designed, however, to be active participants in the process of interaction. Intelligent machines are already able to speak natural languages, answer questions, provide suggestions, and over time their communication skills are expected to parallel or even exceed human communication skills and abilities. This suggests that various forms of AI are active participants in the process of interaction. The Shannon-Weave model may have worked as a helpful model for understanding human to machine communication decades ago and for explaining human-to-human communication. In the age of AI and bots, however, the model does not seem to fully capture the intricacies of human-to-AI and bot interaction.

\section{The Communication as Process Model}

Berlo (1960) was among the first to point out that communication is a complex process rather than a more or less mechanistic exchange of messages. He writes that communication is "dynamic, on-going, 
ever-changing, continuous" (Berlo, 1960, p. 24). According to Berlo, communication as process consists of simultaneity, temporal unfolding, and behavioral interdependence. Communication is, therefore, a relational and interdependent process that envelops over time and requires active participation of all those involved in the communication event or series of events. Reddy (1979) metaphorically compares the intricacies of the communication-as-process model with the notion of toolmakers: all those participating in the process of communication are active toolmakers who should approach the communication event with responsibility and effort.

The communication as process model presupposes equality of participants, which raises new ethical questions. Are AI and bots equal to humans? Will communicating with them as equals provide them with personhood? What would be the consequence of such a development? A journey into other relational theories does not seem to provide definitive answers, either.

\section{Theories of Dialogue}

Theories of dialogue are relationship and interaction-oriented communication theories that provide a valuable theoretical basis for understanding the nature of human communication. They also have a practical application in that they bring to the fore ethical aspects of human encounters and relationships. In the following paragraphs, the focus is on Martin Buber and Mikhail Bakhtin's respective theories of dialogue.

At the core of Buber's theory of dialogue is respect and genuine caring for other human beings and building relationships with others. "In the beginning was relation," writes Martin Buber $(1969$, p. 69). He distinguishes between relationships that range from pragmatic to objectifying and even exploitative, on one hand, and genuine human encounters, on the other. The former relationship, or the $I-I t$ relationship is the subject-object relationship that helps science advance and knowledge accumulate, but when it involves human beings, it becomes dehumanizing and objectifying. The latter relationship, or the I-Thou relationship, is an existential relation between human beings based on openness, genuineness, and mutuality (Buber, 1958a, 1958b, 1965). An I-Thou relationship gives rise to genuine meeting that Buber refers to interhuman or the between - a special existential realm that gets created when one person regards another as a "partner in a living event" (Buber 1965, p. 74).

Can Buber's existential view of relationships provide a theoretical basis for communicating with intelligent machines? If we follow Buber's distinction between two types of relationships, interaction with a machine would fall into the $I-I t$ category. This brings us to the question posed earlier in this article: in what category do AI and bots belong - are they objects or are they human? The answer is not simple. Again, as in the case of the Shannon-Weaver model and the communication as process model, we have arrived at an ethical impasse. In the following step, we will journey through Bakhtin's postmodern and quantum theory inspired view.

Bakhtin's (1986) major focus is on utterances and the manner in which they create an intertwined communication weft - seemingly a disembodied world that reflects the dance of atoms and molecules at the quantum level. An utterance can be monologic or dialogic. A monologic utterance does not have a recipient in mind. In order for an utterance to be dialogic, it must possess addressivity or a recipient orientation. Bakhtin (1986) describes addressivity in this manner: "both the composition and, particularly, the style of the utterance depend on those to whom the utterance is addressed, how the speaker (or writer) senses and imagines his addressees, and the force of their effect on the utterance" (p. 95). Bakhtin's ideas seem like a possible starting point for establishing a theoretical foundation for human-to-AI and bot communication. Bakhtin, however, had humans in mind when writing his texts on dialogue. Extrapolating his ideas to AI and bots poses ethical questions and dilemmas.

Relationships with other human beings are at the heart of ethics, writes Buber (1969). Levinas (1993) views relationships with other human beings as "the core of what is human" and the essence of being human ("Interview"). Through interacting and communicating with AI and bots humans will build relationships with them and may even prefer AI and bots to other humans. Will this potentially result in loss of what it means to be human? Let us hope that with the development of a theoretical foundation for 
human-to-AI and bot interaction and communication questions posed in this section will be answered. We will now focus on a more specific question that refers to linguistic matters.

\section{Language and Word Choices}

Language is not static. It evolves and changes over time, and new words emerge while others fall into oblivion. Advancements in artificial intelligence and robotics have been accompanied by the emergence of new words. Yet, the definitions and meanings are still unclear and somewhat ambiguous. For example, the word bot is increasingly being used instead of the word robot. It is not quite clear, however, whether the word bot refers only to humanoid robots or to all robots. Words such as super-intelligence, artificial intelligence, smart machines, and super-smart machines require some linguistic attention and clear definitions. Some terms such as general intelligence are confusing and in need of linguistic scrutiny.

Pronouns require special attention. Is an intelligent machine an it, a she, a he or they? Will the genderneutral they be appropriate to use when referring to a robot? What criterion are we to use when referring to AI - their name, their shape, their capability, or something else? For example, Watson looks like a computer, but answers Jeopardy questions like a human being and has a human name and a human voice. The now retired industrial bot Baxter looks like a huge robot and has a face of a computer screen with stylized human facial features. How we refer to Watson and Baxter and numerous other intelligent machines is not a simple matter. The way in which we refer to them is likely to impact the way in which we interact with them and relate to them. If, for example, we think of Watson as it, we will likely treat it as a machine. If we think of Watson as a he or they, we may be more likely to establish a relationship with him/them.

Another term that requires attention regards the persons who acquire AI or a bot. Are they owners, companions, friends, partners, pals, or buddies? We typically say that we own a computer, but AI is much more than a computer. This especially refers to humanoid bots that are designed to build relationships with humans. Deciding on the appropriate term will not be simple.

\section{CONCLUSION}

Developments in AI and robotics have been impressive. AI and bots perform a variety of tasks that humans perform, and in many cases outperform humans. AI and bots are also getting smarter and the range of their capabilities is expanding. In many ways, developments in AI and robotics are fascinating. They also require our attention and scrutiny.

Artificial intelligence and bots will continue to advance and they will be increasingly interwoven in the fabric of our everyday lives. Many bots, regardless of form, will be interactive, sentient, and able to express and display emotions. They will also be able to build relationships with humans and participate in various aspects of human life. Some bots are becoming more and more similar to us humans, and as their abilities in the areas of speech, decision making, and relationship building continue to develop, it is likely that some of them will become just like us. A new world of AI and bots has emerged, and with it various challenges and issues. As creators of AI and bots, we, humans, have an ethical responsibility toward our creation. We also have an ethical responsibility toward other humans and future generations. We, therefore, need to understand the developments and we need to understand the challenges and issues in order to act ethically and prudently.

In this article, attention was drawn to the developments in AI and robotics and to the challenges and issues that the new developments raise. Specifically, the challenges and issues identified and addressed include economic and social changes, the possibility of robotic personhood, interaction and communication, and the lack of models and theories that can help explain and promote an understanding of human-to-AI and bot communication. These challenges and issues contain an ethical component to a larger or smaller degree. They also have implications for leadership and decision making.

This article is a call for discussions and conversations about AI and bots and their current and future role in human lives. Futuristic movies tend to portray a somewhat pessimistic picture of the relationship between the world of super intelligent machines and humans. AI designers, on the other hand, tend to 
have a rather optimistic view. Robotics designer David Hanson, for example, predicts that "in the not-toodistant future, Genius Machines will walk among us. They will be smart, kind, and wise . . . together, man [sic] and machine will create a better future for the world" (as cited in Glass, 2017, para. 21). Whether we share Hanson's optimistic view or not, we cannot disregard the fact that AI and bots exist and that they are advancing at a high pace. We, humans, are on the cusp of a new era that will be characterized by increased interaction with various forms of $\mathrm{AI}$ and bots, including humanoid bots. Unlike computers and various other devices that have been developed over the past decades, AI and bots possess characteristics that make them active participants in the world, and, therefore require our close attention.

\section{REFERENCES}

Albrecht, C. (2019, October 2). CaliBurger adds a second Flippy robot to make French Fries. The Spoon. Retrieved from https://thespoon.tech/caliburger-adds-a-second-flippy-robot-to-makefrench-fries/

Allison, L. (2020, April 16). R2D2 to the rescue: Robots are helping to kill coronavirus in hospitals. Newsmax. Retrieved from https://www.newsmax.com/health/health-news/hospitals robots/2020/04/16/id/963221/

Arnett, R.C., \& Arneson, P. (1999). Dialogic civility in a cynical age: Community, hope, and interpersonal relationships. New York: State University of New York.

Axley, S.R. (1984). Managerial and organizational communication in terms of the conduit metaphor. Academy of Management Review, 9(3), 428-437.

Bakhtin, M.M. (1986). Speech genres \& other late essays. Austin: University of Texas Press.

Barnes, J.E., \& Chin, J. (2018, March 3). The new arms race in AI. The Wall Street Journal.

Belton, P. (2019). Roborace motorsport competition, now in its first competitive season. Technology of Business. Retrieved from https://www.bbc.com/news/business-49420570

Berlo, D. (1960). The process of communication. New York: Holt, Reinhart, and Winston.

Bernstein, A., \& Raman, A. (2015, June). The great decoupling: An interview with Erik Brynjolfsson and Andrew Mcafee. Retrieved from https://hbr.org/2015/06/the-great-decoupling

Bostrom, N. (2014). Superintelligence: Paths, dangers, strategies. Oxford: Oxford University Press.

Brynjolfsson, E., \& Mcafee, A. (2014). The second machine age: Work, progress, and prosperity in a time of brilliant technologies. W. W. Norton \& Company: New York.

Buber, M. (1958a). I and thou (2nd ed.). (R.G. Smith, Trans.). New York: Scribner.

Buber, M. (1958b). To hallow this life: An anthology (J. Trapp, Ed.). New York: Harper \& Brothers.

Buber, M. (1965). The knowledge of man. London: G. Allen \& Unwin.

Bucklin, L. (2019, December 9). Robots in finance could wipe out some of Its highest-paying jobs. Newsmax. Retrieved from https://www.newsmax.com/finance/streettalk/robots-finance-highestpaying/2019/12/09/id/945097/

Bunker, T. (2018). AlphaZero AI program's creativity and intuition reaches historical 'Turning Point'. Newsmax. Retrieved from https://www.newsmax.com/newsfront/alphazero-artificial-intelligencechess-chess-play/2018/12/07/id/893578/

Burke, C. (2016, December 19). Mark Zuckerberg: I've built AI butler named Jarvis. Newsmax. Retrieved from https://www.newsmax.com/newsfront/mark-zuckerberg-builds-artificialintelligence/2016/12/19/id/764733/

Burke, K. (1965). Permanence and change: An anatomy of purpose (3rd ed.). Berkeley: University of California Press.

Byrne, J.A. (2017, February 5). Are robots coming to take investor jobs on Wall Street? New York Post. Retrieved from http://nypost.com/2017/02/05/are-robots-coming-to-take- investor-jobs-on-wallstreet/

Coeckelbergh, M. (2012). Can we trust robots? Ethics and Information Technology, 14(1), 53-60.

Coeckelbergh, M. (2014). The moral standing of machines: Towards a relational and non-cartesian moral hermeneutics. Philosophy and Technology, 27(1), 61-77. DOI:10.1007/s13347-013-0133-8

50 Journal of Leadership, Accountability and Ethics Vol. 17(5) 2020 
Cooren, F. (2004). Textual agency: How texts do things in organizational settings. Organization, 11(3), 373-393.

Dean, S. (2020, February 27). The new burger chef makes $\$ 3$ an hour and never goes home. (It's a robot). Los Angeles Times. Retrieved from https://www.latimes.com/business/technology/story/2020-0227/flippy-fast-food-restaurant-robot-arm

Fairhurst, G.T., \& Putnam, L. (2004). Organizations as discursive constructions. Communication Theory, $14,5-26$.

Ford, M. (2015). Rise of the robots: Technology and the threat of a jobless future. Basic Books: New York.

Ford, M. (2016). The rise of the robots: Technology and the threat of mass unemployment. One world Publication: London.

Frank, A. (2018, January 21). Machines teaching each other could be the biggest exponential trend in AI. SingularityHub. Retrieved from https://singularityhub.com/2018/01/21/machines-teaching-eachother-could-be-the-biggest-exponential-trend-in-ai/\#sm.0001k23zgcpe5ff6xea2g1g51 ohr3 in AI

Fromm, E. (1956). The art of loving. New York: Harper and Row.

Gallagher, J. (2017a). Artificial intelligence predicts when heart will fail. BBC News. Retrieved from http://www.bbc.com/news/health-38635871

Gallagher, J. (2017b). Artificial intelligence can identify skin cancer in photographs with the same accuracy as trained doctors, say scientists. Retrieved from http://www.bbc.com/news/health38717928

Glass, N. (2017, February 21). What the faces of our robots tell us about ourselves. CNN. Retrieved from http://www.cnn.com/2017/02/21/design/science-museum-robots-design/index.html

Graham, J. (2018, May 28). Hamburger-making robot Flippy is back at Calif. Chain. USA Today. Retrieved from https://www.usatoday.com/story/tech/talkingtech/2018/05/28/hamburger-makingrobot-flippy-back-serving-300-burgers-

Gunkel, D.J. (2012a). Communication and artificial intelligence: Opportunities and challenges for the 21 st century. communication $+1,1$ (article 1$)$. Retrieved from http://scholarworks.umass.edu/cpo/vol1/iss1/1

Gunkel, D.J. (2012b). The machine question: Critical perspectives on AI, robots, and ethics. MIT Press: Cambridge, MA.

Guzman, A.L. \& Lewis, S.C. (2019). Artificial intelligence and communication: A human-machine communication research agenda. New Media \& Society, 22(1), 70-86. Retrieved from https://journals.sagepub.com/doi/abs/10.1177/1461444819858691

Harrari, N.Y. (2020, June). Who will win the race for AI? Pocket. Retrieved from https://getpocket.com/explore/item/who-will-win-the-race-for-ai?utm_source=pocket-newtab

Heracleous, L., \& Hendry, J. (2000). Discourse and the study of organization: Towards a structurational perspective. Human Relations, 53, 251-286.

Heracleous, L., \& Marshak, R. I. (2004). Conceptualizing organizational discourse as situated symbolic action. Human Relations, 57(10), 1285-1312.

Interview with Levinas (English subtitles). (1993). Retrieved March 15, 2015, from https://www.youtube.com/watch?v=Zvnk6moRmEA

Kodish, S., \& Pettegrew, L S. (2008). Enlightened communication is the key to building Relationships. Journal of Relationship Marketing, 7(2), 151-176.

Levinas, E. (1979). Totality and infinity: An essay on exteriority (Lingis, A. Trans.). The Hague, Martinus Nijhoff.

Marr, B. (2016, April). Why everyone must get ready for the $4^{\text {th }}$ industrial revolution. Forbes. Retrieved from http://www.forbes.com/sites/bernardmarr/2016/04/05/why-everyone-must-get-ready-for4th-industrial-revolution/\#f7d09ea79c98

McChesney, R.W. (2016, February-April). Here comes the real digital revolution. New Philosopher, 11, 85-88. 
McFarland, M. (2017, December). Farmers spot diseased crops faster with artificial intelligence. CNN. Retrieved from http://money.cnn.com/2017/12/14/technology/corn-soybean-aifarming/index.html

Monks, K. (2017). This talking, electric, self-driving bus is coming to a city near you. Ecosolutions. Retrieved from http://www.cnn.com/2016/10/20/world/ollis-electric-bus/index.html

Montagu, A., \& Matson, F. (1983). The dehumanization of man. New York: McGraw-Hill.

Murphy, M. (2019, August 29). Replika: This app is trying to replicate you. Quartz. Retrieved from https://qz.com/1698337/replika-this-app-is-trying-to-replicate-you/

Nash, C. (2017). RealDoll creating artificial intelligence system, robotic sex dolls. Retrieved from http://www.breitbart.com/tech/2017/02/06/realdoll-creating-artificial-intelligence-system-roboticsex-dolls/

Pålshaugen, O. (1998). The end of organizational theory? Language as a tool in action research and organizational development. Amsterdam: John Benjamins.

Papadakis, Z. (2018, September 11). Lifelike pediatric robot creeps out docs in training. Newsmax. Retrieved from https://www.newsmax.com/thewire/lifelike-pediatric-robottraining/2018/09/11/id/881195/

Postman, N. (1999). Building a bridge to the $18^{\text {th }}$ century: How the past can improve our future. New York: Knopf.

Putnam, L.L., \& Fairhurst, G. (2001). Discourse analysis in organizations. In F.M. Jablin \& L.L. Putnam (Eds.), The new handbook of organizational communication (pp. 78-136). Thousand Oaks, CA: Sage

Reddy, M.J. (1979). The conduit metaphor: A case of frame conflict in our language about language. In A. Or ny (Ed.), Metaphor and thought (pp. 164-201). Cambridge: Cambridge University Press.

Ross, A. (2016). The industries of the future. Simon \& Schuster: New York.

Schwab, K. (2016a). The fourth industrial revolution. Crown Business: New York.

Schwab, K. (2016b). The Fourth Industrial Revolution by Klaus Schwab. World Economic Forum. Retrieved from https://www.weforum.org/about/the-fourth-industrial-revolution-by-klaus-schwab

Singh, S. (2017, November 20). Transhumanism and the future of humanity: 7 ways the world will change by 2030. Forbes. Retrieved from https://www.forbes.com/sites/sarwantsingh/2017/11/20/transhumanism-and-the-future-ofhumanity-seven-ways-the-world-will-change-by-2030/\#6d7257947d79

Tannen, D.T. (1998). The argument culture: Moving from debate to dialogue. New York: Random House.

Taylor, J.R., \& Robichaud, D. (2004). Finding the organization in the communication: Discourse as action and sensemaking. Organization, 11(3), 395-413.

Tegmark, M. (2017). Life 3.0: Being human in the age of artificial intelligence. Alfred A. Knopf: New York.

Tompkins, P., \& Wanca-Thibault, M. (2001). Organizational communication: Prelude and prospect. In F. Jablin \& L. Putnam (Eds), The New handbook of organizational communication (pp. xvii-xxx). Thousand Oaks, CA: Sage.

Turing, A.M. (1950). Computing machinery and intelligence. Mind, 59, 433-460. Retrieved from http://www.loebner.net/Prizef/TuringArticle.html

Wolf, Z.B. (2019, August 24). The robots are coming for your jobs. CNN. Retrieved from https://www.cnn.com/2019/08/24/politics/economy-us-workforce-automation/index.html 